\begin{tabular}{|c|c|c|}
\hline $\begin{array}{l}\text { PKS } \\
\text { PUBLIC } \\
\text { KNDOLEDGE } \\
\text { PROJECT }\end{array}$ & $\begin{array}{c}\text { Revista de GEOGRAFIA } \\
\text { (RECIFE) } \\
\text { http://www.revista.ufpe.br/revistageografia }\end{array}$ & $\begin{array}{l}\text { OJS } \\
\text { OPEN } \\
\text { JOLYNAL } \\
\text { SYSTEMS }\end{array}$ \\
\hline
\end{tabular}

\title{
ENSINO DE GEOMORFOLOGIA: DESAFIOS NA FORMAÇÃO INICIAL
}

\author{
Carla Juscélia de Oliveira Souza ${ }^{1}$
}

${ }^{1}$ Docente no Programa de Pós-Graduação em Geografia (PPGEOG) e do Departamento de Geociências (DEGEO) da Universidade Federal de São João del-Rei /UFSJ. Coordenadora do Grupo de Estudos e Pesquisas em Geografia, Educação e Riscos (GEPEGER). Email:carlaju@ufsj.edu.br

Artigo recebido em 17/07/2018 e aceito em 18/08/2018

\section{RESUMO}

O artigo tem como objetivo apresentar e discutir três desafios presentes no ensino de geomorfologia. A concepção de ensino e aprendizagem, os conteúdos e o raciocínio geomorfológico e o pensamento e visualização espacial são a base dos referidos desafios para o professor de geomorfologia. Este precisa considerar o aluno no centro do processo de ensino-aprendizagem, e os conteúdos de geomorfologia como meios para desenvolver o pensamento e o raciocínio geomorfológico na resolução de problemas. Essa discussão se fundamenta em pesquisa de doutoramento e na experiência profissional da autora.

Palavras-chaves: ensino-aprendizagem, raciocínio geomorfológico, pensamento espacial

\section{GEOMORPHOLOGY TEACHING: CHALLENGES IN INITIAL TRAINING}

\begin{abstract}
The article aims to present and discuss three challenges present in the teaching of geomorphology. The teaching and learning conception, the contents and the geomorphological reasoning and the spatial thought and visualization are the basis of the challenges for the professor of geomorphology. This needs to consider the student at the center of the teaching-learning process and the contents of geomorphology as a means to develop thinking and reasoning geomorphological problem solving. This discussion is based on doctoral research and the author's professional experience.
\end{abstract}

Keywords: Teaching-learning, geomorphological reasoning, spatial thinking

\section{INTRODUÇÃO}

Pensar e discutir o ensino de Geomorfologia na formação inicial abrem espaço para diálogos referentes ao tema, com base em diferentes abordagens que cabem no sistema, complexo, da formação profissional. Nesta oportunidade, fez-se a escolha pelo recorte 
referente à dimensão do ensino e da aprendizagem dos conteúdos e do raciocíneo geomorfológico, que perpassam por conhecimentos pedagógico, geomorfológico e espacial.

Inicialmente, o texto discute a concepção de ensino presente na ação pedagógicodidática de professores de Geomorfologia e aquela almejada pela aprendizagem significativa, ainda que estes não tenham necessariamente formação em licenciatura. Por esse motivo, considera-se relevante tratar esse assunto em eventos científicos de Geomorfologia ou em pesquisas na interface Educação e Geomorfologia, como vem sendo realizado por Souza (2009), Oliveira (2010), Afonso (2015) e Cruz (2017), e outros autores que discutem o elemento relevo como componente espacial e físico-natural nos conteúdos de formação de professores e no ensino na educação básica, como Carvalho (1999), Rocha (2009) e Morais (2011).

Fundamentado em Souza (2003, 2009), Souza e Valadão (2015) e, principalmente, na trajetória e na prática profissional da autora, com os conhecimentos e as dificuldades observadas entre graduandos do bacharelado e da licenciatura em Geografia, com conteúdo de Geomorfologia, propõe-se neste texto apresentar e discutir os desafios, no ensino, durante a formação inicial.

Para este texto, foram escolhidos três desafios, sabendo-se que existem outros no exercício da docência no contexto da formação inicial em Geografia.

Um dos desafios refere-se à questão da concepção de ensino adotada pelo professor de Geomorfologia. A concepção que se tem sobre ensino influencia na escolha pedagógicodidática adotada pelo professor, na escolha e condução do conteúdo e do conhecimento que se deseja construir e na maneira de ver e perceber os discentes, entre outros aspectos. $\mathrm{O}$ segundo desafio compreende a definição do conteúdo a ser ensinado, ainda que se tenha um rol prescrito no currículo acadêmico. Esse conteúdo pode compreender abordagens que priorizem conceitos, fatos e teorias, ou o pensamento e o raciocínio geomorfológico por meio dos conteúdos. O tipo de concepção que se tem de ensino irá influenciar também na abordagem dos conteúdos. Um terceiro desafio refere-se à dimensão da linguagem e representação. Neste último, a atenção está sobre as dificuldades e habilidades com a linguagem gráfica e a visualização espacial necessárias na leitura e representação do fenômeno geomorfológico, interpretado em sua espacialidade. Entender e conhecer essas possíveis dificuldades e habilidades espaciais, no processo de ensino-aprendizagem de Geomorfologia, constituem desafio quando estes passam a fazer parte também das preocupações docente com o referido processo de formação. 
Esses três aspectos são concebidos como desafios ao se pensar no ensino de Geomorfologia à luz do ensino-aprendizagem na perspectiva interacionista/construtivista; ao considerar a importância da construção do conhecimento, entendendo e tomando para o ensino a ciência de referência, no caso, a Geomorfologia/Geografia e por considerar fundamental estar atento à dimensão do processo cognitivo referente ao pensamento e à representação espacial entre os graduandos.

Os referidos aspectos se tornam desafios para os docentes ao se considerar a tradição no ensino de Geomorfologia centrada nos conteúdos, no professor e nos resultados (notas). Para além dos aspectos formais e, muitas vezes, burocráticos existentes no trabalho do professor, seja na educação básica ou na formação profissional, há a dimensão dos sujeitos (discente e docentes) envolvidos nessa formação. Portanto, considerar o ensino hoje de Geomorfologia na formação inicial, em outra perspectiva, em relação ao ensino consolidado na graduação, constitui, aos olhos da autora, desafios na/da formação de Geomorfologia para os docentes.

Poder-se-iam elencar outros desafios para essa discussão, tratados individualmente, na maioria das vezes, sob abordagens diversas. Mas, aqui são entendidos como parte de um todo complexo (Figura 1), interligados e com dimensões variadas, de acordo com o entendimento e interpretação de cada docente.

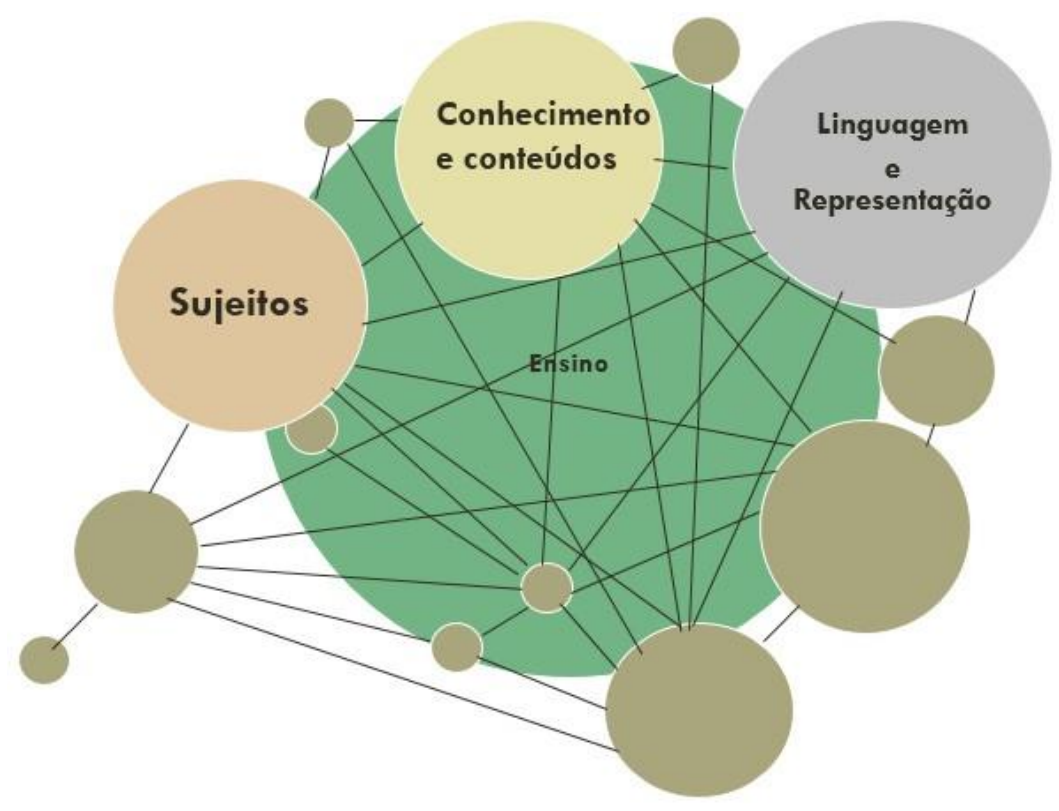

Figura 1: Desafios em rede.

Org. Autora, 2018. 
Cada desafio pode ser considerado maior ou menor entre os professores de Geomorfologia, uma vez que cada um tem a sua própria trajetória sócio-histórica e cultural de formação profissional e pessoal.

Introduzidas essas ideias e concepções, o texto continua discutindo cada desafio, agora organizado em tópicos que dialogam entre si. Para finalizar, são apresentadas algumas considerações sobre o assunto discutido e as referências citadas no escopo do trabalho.

\section{ENSINO-APRENDIZAGEM DE GEOMORFOLOGIA}

A perspectiva teórica e filosófica das ideias e discussões neste texto fundamenta-se na concepção de que pensar o ensino implica considerar a aprendizagem do outro que participa da interação professor-aluno, de maneira dialética. Logo, não se tem o entendimento da aprendizagem como consequência direta do ensino, na lógica processo-produto, como se fosse suficiente comunicar um saber para que o discente o aprendesse (ALTET, 2000). Nessa perspectiva, a aprendizagem se dá em processo mecânico de associação de estímulos e respostas provocados e determinados pelas condições externas (POZO, 2002), revelando existir a aprendizagem do objeto quando o sujeito se mostra capaz de repetir e reproduzir tal conhecimento. Mas, na discussão proposta neste texto concebe-se a aprendizagem em processo de ensino que se preocupa com a articulação entre ensino-aprendizagem em uma prática relacional, numa dada situação específica (processos cognitivos) e num contexto específico (formação).

Etimologicamente, em latim insignare (ensinar) significa sinalizar ou impor a sua marca (ALTET, 2000), concebendo no ato de ensinar a transmissão de informação, em uma perspectiva unidirecional, do professor para o aluno. No ato de ensinar, na contemporaneidade, a relação professor-aluno permanece fazendo parte do processo, mas as finalidades educativas e formativas mudaram. Em qualquer uma delas, busca-se a formação da pessoa para, em situação presente e futura, utilizar-se do conhecimento na resolução de problemas, operacionalizando os fundamentos teóricos e práticos susceptíveis de funcionarem como 'recursos' a serem mobilizados, apropriadamente, em situações concretas.

A concepção de ensino que considera a perspectiva ensino-aprendizagem como processo de mão dupla ou 'face de uma mesma moeda' (ALTET, 2000) fundamenta-se nas teorias interacionistas e construtivistas, das quais Vygotsky, Lúria, Leontiev (Psicologia genético-dialética), Piaget, Bruner, Ausubel, Inheldere Piaget (Psicologia Genético- 
cognitiva), e outros, são representantes, considerando e respeitando as especificidades presentes na teoria de cada um desses pesquisadores. Nessas teorias, são consideradas importantes a trajetória social e cultural dos alunos (Vygotsky), assim como os aspectos genético-cognitivos (Piaget), pois influenciam nas características, condições e ritmos da aprendizagem entre os discentes.

A aprendizagem é um processo de conhecimento, de compreensão de relações, em que as condições externas atuam mediadas pelas condições internas, apoiam-se na explicação de que os esquemas internos constroem-se e têm como um dos fundamentos, a supremacia da aprendizagem significativa. Nesta, o significado é o eixo motor de toda a aprendizagem e a motivação intrínseca da aprendizagem desejada. Esta se apoia no interesse por resolver um problema, por estender a clareza e o significado, cada vez mais amplo, do objeto investigado, seja ele o espaço vital, o território onde o indivíduo vive e/ou os fenômenos naturais e sociais. Nesse aspecto, a aprendizagem é "processo de inferências e transferências entre os conhecimentos que se possui e os novos problemas-situações que são propostos" (HERNANDEZ, 1998, p. 74), dinâmica construída na interação sujeito-objeto, sujeito-sujeito, considerando as dimensões cognitiva, social, cultural, científica e visão de mundo.

A trajetória escolar dos alunos que chegam à universidade influenciará, em grande parte, o ritmo e a dificuldade no processo de formação profissional. Na fase de educação básica, espera-se que as noções e os conhecimentos elementares no campo do raciocínio espacial, matemático, linguístico, artístico, entre outros, sejam trabalhados e desenvolvidos, satisfatoriamente, como base para outros conhecimentos (SOUZA, 2009). Mas, segundo a autora, a realidade observada na graduação entre os alunos que ingressam nos cursos de Geografia mostra dificuldades diversas, referentes ao raciocínio matemático, à escrita, ao pensamento e visualização espacial. Essas dificuldades interferem no processo de aprendizagem de conteúdos presentes na Geomorfologia. Esse aspecto, ligado à cognição e pensamento espacial, será discutido no item três.

Muitas vezes, o aluno do curso universitário, apesar de apresentar os instrumentos intelectuais do pensamento formal, não irá aplicá-los a todos os conteúdos com os quais se deparar, ou seja, sua capacidade de raciocinar formalmente não é suficiente para que aplique essa "forma" para outros conteúdos (SARAVALI, 2005). Esse fato foi observado por Souza (2009) ao estudar o conhecimento e as dificuldades apresentados por alunos de Geografia durante as disciplinas de Geomorfologia. Segundo a autora, entre os sujeitos de sua pesquisa, $35 \%$ indicaram, como uma de suas dificuldades, o operacionalizar com as teorias, estudadas 
em Geomorfologia, na interpretação de um fenômeno, principalmente durante o campo, conforme pode ser observado nas citações seguintes: "Minha principal dificuldade não foi tanto compreender a teoria em si, mas visualizá-la e, sobretudo, identificar as formas e processos no campo. Talvez pela falta de prática e experiência (Lilás, 2007)" e "Conceitos, abstrações dos processos vistos no campo e dificuldade em descobrir os processos apenas com a observação da paisagem (Gerânio, 2007)" (SOUZA, 2009, p.111).

Essas citações indicam outra questão a ser considerada na formação inicial, a relação teoria e prática como concepção e estratégia de ensino que considerem a construção de um conhecimento que seja mobilizado em situações-problema. Para isso, é importante o envolvimento dos alunos em atividades, cujas estratégias de mobilização dos conhecimentos considerem teoria e prática como processo de articulação entre ambas, ao mesmo tempo em que são realizadas. Dessa maneira, "conjuga-se a perspectiva da racionalidade técnica com a perspectiva epistemológica da prática" (ALARCÃO, 2008, p. 178) e da teoria, pois conforme o autor "sem a experiência prévia, os alunos não podem refletir sobre a sua atuação. Sem referentes teóricos, não podem observar e descrever de forma significativa (ALARCÃO, 2008, p. 178). Essa citação é feita para se discutir a formação do profissional professor e a importância da interação teoria-prática. Entende-se que para a formação do profissional geógrafo, que irá atuar em situação e contexto diversos, na resolução de questões com nível de dificuldades variado, essa interação não deve ser diferente. Essa perspectiva tem base na teoria da flexibilidade cognitiva (SPIRO et. al., 1987) no campo da didática. Essa teoria

[...] privilegia o desenvolvimento de capacidades de transferência de conhecimentos, a sua adaptação e reconstrução das situações concretas, a aprendizagem à base de casos e resolução de problemas, o desenvolvimento de conhecimentos estruturantes do pensamento, as representações múltiplas e a combinação e recombinação de conceitos (ALARCÃO, 2008, p.179).

Embora Alarcão (2008) esteja discutindo a questão da didática na formação de professores, acredita-se que tal teoria deva ser considerada para as demais formações profissionais.

Os jovens e adultos que chegam à universidade para uma formação específica, no presente caso, em Geografia, podendo especializar-se em Geomorfologia, desempenharão seu trabalho, fundamentando-se na análise e interpretação dos fenômenos espaciais, considerando sua localização, extensão, correlação, conexão, processos, espacialidade como princípios da Geografia. É necessário, portanto que esses profissionais saibam operacionalizar com esses 
princípios, fundamentados pelas teorias e conceitos que subsidiam o pensamento geográfico e o geomorfológico. Esse conhecimento pode ser construído na interação teoria-prática.

De acordo com Bates (1995), o ensino universitário deve ser discursivo, interativo, adaptativo e reflexivo, ou seja:

\begin{abstract}
Discursivo: um ambiente deve ser criado onde os estudantes e o professor podem comunicar objetivos e conceitos entre si; Interativo: o estudante deve realizar ações para demonstrar o aprendizado e o professor deve fornecer feedback; Adaptativo: o professor deve usar a informação sobre a compreensão dos estudantes sobre os conceitos para determinar futuras atividades de aprendizado; Reflexivo: o professor deve encorajar os estudantes a refletir no feedback em relação aos objetivos instrucionais (BATES ${ }^{1}, 1995$ apud YENEMOTO, 2004, p. 48).
\end{abstract}

Para os jovens e adultos, na formação inicial, a aprendizagem é mais efetiva quando se tem os desafios e a resolução de problemas como ação pedagógico-didática. Yenemoto (2004), ao discutir a questão da aprendizagem do adulto, afirma que este está mais ligado a objetivos, à resolução de problemas e desafios com os quais se confronta na vida cotidiana, diferentemente das crianças, mais abertas para acolher informações (SOUZA, 2009). Portanto, têm-se três aspectos importantes nesse fato: o lugar do aluno no processo de ensino, a metodologia adotada e o conteúdo como meio e forma para desenvolver o pensamento na resolução de problemas em situações diversas.

Levando-se em consideração o ensino de Geomorfologia, para a formação do profissional em Geografia, ou mesmo para o geomorfólogo, as ideias e discussões apontadas permitem observar e dizer que há um desafio para a academia como um todo, que se mantém no lugar central do ensino com a valorização, principalmente, do conteúdo. Isso não significa dizer que os conteúdos não sejam importantes, mas considerar a finalidade e o papel deles na formação profissional.

\title{
CONTEÚDOS E O RACIOCÍNIO GEOMORFOLÓGICO
}

Para iniciar esse item, parte-se de um fato e de uma questão para o leitor, para que se possa, então, introduzir a linha de raciocínio que a autora deseja construir nesta parte do texto. $\mathrm{O}$ fato refere-se à diversidade de eixos presentes nos Simpósios Nacionais de Geomorfologia (SINAGEO), ocorridos desde 1996, quando ocorreu a sua primeira edição, em Uberlândia. Desde então, a cada dois anos, o evento é realizado em diferentes cidades e estados brasileiros. Cada evento traz uma proposta de eixos temáticos, conforme quadros 1 e 2 . Esses

BATES, A. W. Technology: Open learning and distance education. Nova York: Routledge, 1995. 
eixos representam, em parte, os assuntos e conteúdos em discussão no âmbito das pesquisas e da formação acadêmica.

Quadro 1: Eixos temáticos presentes no SINAGEO, 2018.

\begin{tabular}{|l|}
\hline \multicolumn{1}{|c|}{ SINAGEO 2018 - URCA - Crato - Ceará } \\
\hline Geomorfologia Estrutural, Neotectônica e Carste \\
\hline Geomorfologia do Quaternário e Geocronologia \\
\hline Geomorfologia Costeira \\
\hline Geomorfologia de Ambientes Semiáridos \\
\hline Geomorfologia de Sistemas Fluviais e Lacustre \\
\hline Dinâmicas de Vertentes e Interações Pedogeomorfológicas \\
\hline Geomorfologia e planejamento ambiental \\
\hline Ensino de Geomorfologia e formação do Geomorfólogo \\
\hline Geodiversidade e Patrimônio Geomorfológico \\
\hline Geotecnologias, Modelagem e Mapeamento Geomorfológico \\
\hline
\end{tabular}

Org. autora, 2018.

Quadro 2: Eixos temáticos presentes no SINAGEO, 2008.

\begin{tabular}{|l|}
\hline \multicolumn{1}{|c|}{ SINAGEO 2008 - UFMG - Belo Horizonte - MG } \\
\hline Dinâmica crustal e domínios morfoestruturais como fatores da diversificação de paisagens \\
\hline Dinâmica das paisagens costeiras e submarinas \\
\hline Processos fluviais e dinâmica de bacias \\
\hline Vertentes: formas, processos e materiais \\
\hline Geomorfologia Aplicada \\
\hline Epistemologia da Geomorfologia - Sessão Especial: olhares contemporâneos da Geomorfologia \\
\hline Evolução e estruturas dos grandes domínios de relevo na América Latina \\
\hline
\end{tabular}

Org. autora, 2018.

Observando-se cada eixo, independentemente do ano, notam-se as abordagens que consideram o mega e macro relevo, com desdobramentos para os processos geológico e geomorfológico pertinentes à escala espacial e temporal considerada. Verifica-se também as abordagens do meso e micro relevo, com extensão para a morfodinâmica na escala da vertente e ou fluvial, assim como para os agentes e processos específicos que dão identidade a determinados tipos de formas e processos, como as cársticas, litorâneas, lacustres, entre outras. A depender da relação escala espacial e temporal de abordagem do fenômeno geomorfológico, os trabalhos podem fundamentar-se na perspectiva historicista, funcionalista, sistêmica e aplicada dos estudos geomorfológicos. Estes podem estar associados a outras áreas de conhecimento, como o estudo das tecnologias, em especial, ao das geotecnologias, que auxiliam o estudo dos fenômenos geomorfológicos em diferentes escalas espaciais. 
Ainda de acordo com a análise dos eixos, observam-se os que se dedicam à questão teórica e epistemológica da Geomorfologia, seja como ciência, área de conhecimento ou de ensino e formação. Verificam-se conteúdos e abordagens distintos, cujas finalidades podem ser para a formação profissional, para a pesquisa, para a aplicação e/ou para o ensino na educação básica ou no ensino superior. Esse fato leva a pensar na diversidade e nas possibilidades de assuntos e conteúdos apresentados na formação acadêmica como disciplinas, no âmbito do conhecimento geomorfológico e suas aplicações.

Em pesquisa de doutoramento Cruz (2017) considerou trinta e cincos cursos de Geografia, de universidades federal e estadual, e levantou a relação de disciplinas obrigatórias (Quadro 3) e as optativas ligadas à Geomorfologia (Quadro 4).

Quadro 3: Disciplinas relacionados ao conteúdo de Geomorfologia em cursos de Geografia.

\begin{tabular}{|c|c|c|}
\hline & Disciplinas obrigatórias & $\mathrm{N}^{\circ}$ de IEF \\
\hline \multirow{6}{*}{ Básicas } & Geomorfologia & 18 \\
\hline & Geomorfologia Geral & 10 \\
\hline & Geomorfologia I & 8 \\
\hline & Geomorfologia II & 4 \\
\hline & Fundamentos de Geomorfologia & 2 \\
\hline & Introdução à Geomorfologia & 1 \\
\hline \multirow{15}{*}{ Especificas } & Geomorfologia Estrutural & 5 \\
\hline & Geomorfologia Costeira & 4 \\
\hline & Geomorfologia Fluvial & 3 \\
\hline & Geomorfologia Continental & 3 \\
\hline & Geomorfologia Estrutural e Climática & 2 \\
\hline & Geomorfologia Fluvial e Hidrografia, & 2 \\
\hline & Geomorfologia Climática e Estrutural & 2 \\
\hline & Geomorfologia Básica e Estrutural & 1 \\
\hline & Geomorfologia Continental II & 1 \\
\hline & Geografia Física 1 (Geomorfologia Intertropical) & 1 \\
\hline & Geomorfologia Escultural e Aplicada & 1 \\
\hline & Geomorfologia Escultural & 1 \\
\hline & Geomorfologia e Ambiente & 1 \\
\hline & Geomorfologia e Ambiente I & 1 \\
\hline & Geomorfologia e Ambiente II-A & 1 \\
\hline \multicolumn{3}{|c|}{ Fonte: Adaptado de Rodrigues (2012). } \\
\hline
\end{tabular}

Fonte: Cruz (2017, p. 111) 
Quadro 4: Disciplinas optativas relacionadas à Geomorfologia.

\begin{tabular}{|l|c|}
\hline \multicolumn{1}{|c|}{ Disciplinas Optativas } & No de IEF \\
\hline Geomorfologia Aplicada & 4 \\
\hline Geomorfologia Aplicada a Engenharia & 2 \\
\hline Geomorfologia do Brasil Aplicada ao Ensino & 2 \\
\hline Geomorfologia Climática & 2 \\
\hline Geomorfologia Litorânea & 2 \\
\hline Mapeamento Geomorfológico & 2 \\
\hline Tópicos especiais em Geomorfologia & 1 \\
\hline Geomorfologia Aplicada ao Planejamento Ambiental & 1 \\
\hline Geomorfologia do Quaternário & 1 \\
\hline Geomorfologia do Quaternário e Mudanças Climáticas Globais & 1 \\
\hline Geomorfologia Fluvial & 1 \\
\hline Geomorfologia I e Geomorfologia Aplicada & 1 \\
\hline Geomorfologia Instrumental & 1 \\
\hline Geomorfologia Tropical & 1 \\
\hline Prática de Campo em Geologia e Geomorfologia. & 1 \\
\hline Tópicos de Geomorfologia & 2 \\
\hline
\end{tabular}

Fonte: Cruz (2017, p. 112)

Segundo Cruz (2017, p.68),

Dentre as subdivisões da Geomorfologia apresenta-se a Geomorfologia Climática, Estrutural, Costeira, Continental, Regional, Aplicada, Dinâmica, Fluvial, Cárstica, Glacial, de Vertentes, do Quaternário, etc. Ainda podem ser citadas subdivisões mais recentes como a Geomorfologia Antrópica, Urbana, Submarina, Ecológica e até Planetária.

Diante do exposto, faz-se a questão: apesar da diferença entre os eixos e disciplinas, com semelhança entre alguns, todos compreendem, entre os conteúdos dos diferentes assuntos apresentados, conceitos estruturantes importantes no raciocínio geomorfológico. Que conceitos são esses e que precisam ser construídos durante a formação para serem mobilizados durante o raciocínio geomorfológico?

Souza (2009), em pesquisa de doutoramento, discute essa questão, propondo uma reflexão sobre os conceitos-chave que devem ser garantidos e estão presentes no raciocínio geomorfológico. Segundo a autora:

Pode parecer óbvio e banal, mas o entendimento do conceito de relevo é fundamental, principalmente, quando transposto, também, para a dimensão metafísica do objeto que o termo relevo dá significado. Esse objeto pode apresentar-se em diferente escala espacial [...]. Além desse conceito, há o de 
processos geomorfológicos e o de escalas espacial e temporal, conceitos mais gerais e amplos[...] (2009, p.33, grifo nosso).

Esses conceitos que podem parecer banais e de uso corriqueiro no cotidiano, constituem conceitos científicos que medeiam a ação do homem com as coisas e fenômenos da 'realidade' por meio do pensamento, no caso, o pensamento e o raciocínio geomorfológico. Para esse movimento intelectual, é necessário ao sujeito ser capaz de transitar entre as diferentes escalas espacial e temporal que o relevo, identificado em suas formas, é apreendido e interpretado (SOUZA, 2009). Para a apreensão do relevo, este é concebido e estudado com base na taxonomia e ou no método de compartimentação dele, como o proposto por Ab'Saber (1969).

[...] concebe-se as formas de relevo como unidades que contêm outras menores que, por sua vez, contêm outras cada vez menores, e assim sucessivamente. Nessa perspectiva, pode-se pensar a menor forma, como a encontrada na $8^{\mathrm{a}}$ ordem de grandeza, segundo a proposta de Cailleux e Tricart (1959), a encontrada no $6^{\circ}$ táxon, conforme Ross (1992) ou, ainda, as formas identificáveis nos compartimentos topográficos propostos por Ab'Saber (1969) (SOUZA, 2009, p.35, grifo nosso).

Ainda segundo a autora,

[...] o relevo, que pode ser concebido como uma forma física em si mesma, que apresenta tamanho e características físicas internas e externas, disponível para ser descrita e nomeada [...] pode, ainda, constituir-se uma expressão materializada da interação de processos internos e externos da Terra, no tempo e no espaço, como pontuado por Tricart (1986), Marinho (1995) e outros. [...] o relevo constitui a fina e dinâmica superfície de contato entre litosfera e biosfera (ROSS, 1996) em que se desenvolvem todos os tipos de vida, os quais ocorrem sobre unidades de relevo, há tempos classificadas e nomeadas (SOUZA, 2009, p.44).

Isso significa dizer que o relevo como um objeto componente do espaço apresenta tributos internos e externos "resultantes" da inter-relação com os demais componentes espaciais físico-naturais e antrópicos que contribuem para a sua espacialidade. O grau e tipo de inter-relação, e dependência, varia em função da escala espacial e temporal do fenômeno geomorfológico considerado, podendo este ser analisado à luz da ideia de sistemas geomórficos em equilíbrio dinâmico ou em estado estacionário independente do tempo (SCHUMM e LICHTY, 1973).

A apreensão do relevo, como objeto metafísico, não se dá em um só 'golpe de vista' como apresentado e ilustrado por meio de imagens gráficas (bloco-diagrama, perfil 
topográfico, carta topográfica, entre outras) ao fazer referência ao relevo como forma durante o ensino. Mas, deve ocorrer por meio do raciocíneo geomorfológico que compreende um pensamento espacial da forma, articulado com processos geomorfológico, e ou geológico, e em situação específica de tempo e espaço, na qual o relevo (físico e metafísico) é visualizado e interpretado.

Quanto à escala, assim como Souza (2009) e outros, Köhler (2001, p. 22) ao discutir essa questão na análise geomorfológica faz a seguinte referência,

Quanto menor a escala espacial de observação de um fenômeno geomorfológico contínuo (não catastrófico), mais lenta é sua transformação (dinâmica) e a recíproca é verdadeira. [...] quanto menor a escala espacial adotada, maior a influência dos processos endógenos, que por sua vez se referem ao tempo geológico mais antigo. Neste caso, a recíproca também é verdadeira.

Outro conceito-chave é o de 'processos geomorfológicos'. Este é considerado por Souza (2009, p.56) com base na seguinte citação:

$\mathrm{Na}$ atualidade, sabe-se da variedade de agentes, fatores, mecanismos, condicionantes e processos, que participam e influenciam o aspecto do relevo. As ações de transferência de energia e matéria e os processos que contribuem para as modificações e elaboração das formas de relevo e das vertentes - na interface litosfera, biosfera, hidrosfera e atmosfera, independentemente, dos seus agentes (naturais ou antrópicos), de sua intensidade, frequência e magnitude - correspondem a processos geomorfológicos.

De acordo com Casseti (1991, p. 63), entende-se por processo geomorfológico, “[...] todo e qualquer fenômeno responsável por alterações evolutivas das vertentes. São, portanto, os responsáveis pela esculturação das vertentes, representando a dinâmica externa, envolvendo as seguintes etapas: abrasão, transporte e acumulação". Nessa definição, o autor destaca os processos físicos e remete à ideia inicial de atuação de processos naturais nas vertentes. Segundo Souza $(2009,56)$ :

Gregory (1992) [...] faz referências aos estudos sobre processos geomorfológicos, destacando os impactos das atividades humanas sobre esses processos e seus "resultados", que podem aparecer nas vertentes, nas planícies fluviais e em toda uma bacia hidrográfica. Embora seja uma importante unidade de análise, a vertente compõe e inter-relaciona-se com outras unidades. Assim, pensar processos geomorfológicos não significa restringir-se ao estudo da vertente, mas ao estudo dela em interação com os demais ambientes que a contêm. 
O entendimento e a mobilização cognitiva dos três conceitos-chave, aplicados na interpretação de um fenômeno, devem fazer parte do raciocínio geomorfológico. Para isso, é necessário transitar entre as escalas espacial e temporal do relevo na ação de apreendê-lo e interpretá-lo, para assim compreender os processos geomorfológicos ou geológicos atuantes nessas escalas. Com base nesses conceitos-chave, outros se desdobram em função das abordagens de estudos, seja abordagem geológica, geográfica ou hidrológica, entre outras, que passam a compor conteúdo nas disciplinas de geomorfologia (SOUZA, 2009, SOUZA, 2015).

Para a construção desses conceitos, práticas pedagógicas simples podem ser realizadas, como a elaboração de modelos reduzidos (maquete) de um recorte espacial da realidade, tendo o sujeito como centro do processo do ensino-aprendizagem (Figuras 2, 3 e 4).
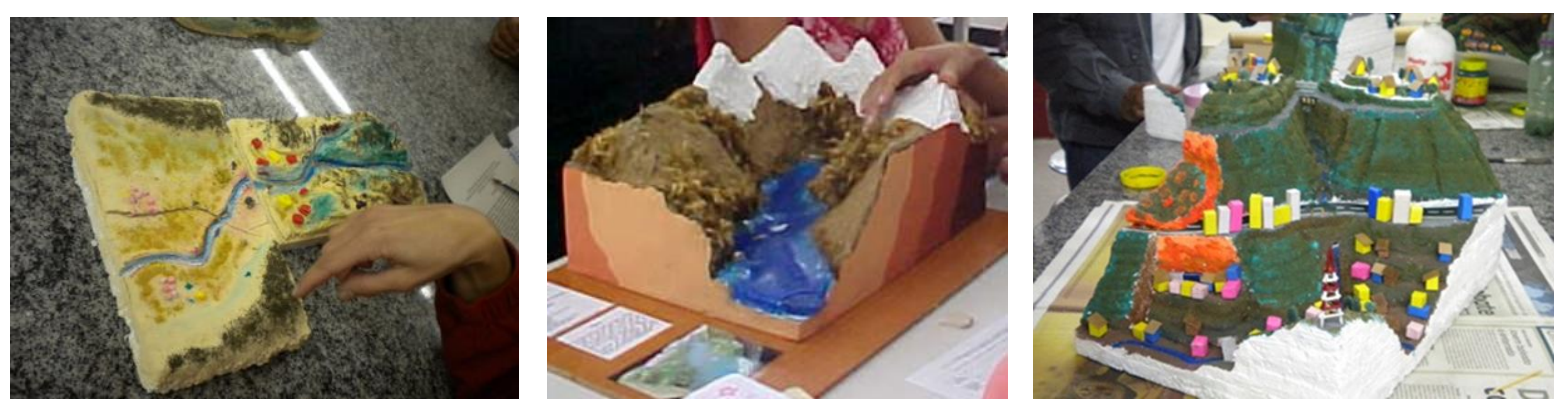

Figuras 2, 3 e 4: representações de formas de relevo em escala geográfica diferente.

Cada uma das representações exemplificadas acima demanda pensamento espacial, considerando a posição, ocorrência e distribuição dos elementos que compõem o espaço representado e, em especial, os componentes do relevo, considerando tipologia, forma e estrutura. Estas como categorias de análise espacial referentes à forma e função, discutidas por Santos (1985) e aplicadas à geomorfologia por Afonso (2015). Segundo a autora, forma/função remete ao espaço e estrutura/processo remete ao tempo, sendo que,

[...] formas como sendo os elementos visíveis no espaço, objetos (como casas, prédios, rodovias, parques, equipamentos de infra-estrutura, veículos, rochas, formas de relevo, cultivos, vegetação, animais, fenômenos meteorológicos etc.) que podem ser descritos por suas propriedades geométricas, cor, volume etc. Cada uma dessas formas possui ou possuiu alguma função (uma tarefa, uma atividade, um significado ou uma funcionalidade, conduzindo um movimento ou estando associada a algum simbolismo). A estrutura reflete a organização entre os componentes do espaço geográfico e das relações dos mesmos entre si, constituindo o aspecto "invisível" que relaciona as diversas funções desempenhadas pelas/nas formas espaciais, podendo ser descrita conforme o arranjo dos componentes, o grau e tipo de interação e/ou proximidade entre os mesmos etc. O processo corresponde à dinâmica, ao aspecto relacionado às atividades correntes e às transformações ocorridas nas demais categorias ao longo da história, tendo 
relação com o surgimento (formação) e com as alterações ocorridas nas demais categorias ao longo do tempo (AFONSO, 2015, p. 82).

No âmbito do pensamento, o conteúdo relevo/forma e espaço, representado nos três modelos físicos das figuras 2,3 e 4, mobilizou habilidades específicas propostas por Souza (2009, p.96) e modelos mentais. Essas habilidades referem-se a:

\begin{abstract}
"Identificar as tipologias de formas e conhecer as suas nomenclaturas; comparar formas e diferenciar nomenclaturas; diferenciar os conceitos: agente, processo, forma e condicionante; identificar os diferentes processos dinâmicos; entender a relação nomenclaturas-conceitos-contexto teóricogeomorfológico; analisar a relação forma-escala espacial e temporal; explicar a gênese do relevo, a partir da interação dos processos geomorfológicos, processos geológicos, condicionantes nas escalas espacial e temporal; reconhecer as diferentes tipologias de formas em carta topográfica; reconhecer as diferentes tipologias de formas em desenhos e modelos tridimensionais; visualizar as formas de relevo, a partir das representações (SOUZA, 2009, p.96).
\end{abstract}

Nos casos em que a estrutura e atributos internos são representados, a habilidade de visualização espacial, como percepção e rotação espacial, é necessária e portanto precisa ser mobilizada entre os graduandos. Essas habilidades são operacionalizadas em modelos mentais, construídos, concomitantemente ou não, com os modelos físicos. Modelo mental,

[...] é uma forma de organizar nosso conhecimento sobre um determinado objeto, processo ou fenômeno que usamos para pensar sobre eles por meio de simulação mental. Esses modelos capacitam-nos a realizar ações inteiramente na imaginação. Isso permite-nos internalizar as representações que criamos para as coisas e os estados de coisas no mundo e processá-los como se fossem externos (BORGES, 1999, p. 91).

Em pesquisa de mestrado, Bertolini (2010), e de doutoramento Cruz (2017) trabalham com essas habilidades durante proposta de práticas didático-pedagógicas envolvendo conteúdo de Geomorfologia, utilizando o Google Earth. Em um dos exemplos, Cruz (2017) utilizou o referido recurso para aplicar o índice de Hack na identificação de setores anômalos e rupturas no relevo, entre outras atividades propostas pela autora e por Bertolini (2010).

Pode-se afirmar que essas habilidades e os conceitos-chave encontram-se presentes no pensamento e raciocínio geomorfológico, seja para abordar a Geomorfologia estrutural, tectônica, litorânea, climática, tropical, entre tantas outras possibilidades de estudos. Assim como são objetos de preocupação do professor os demais conteúdos, técnicas e ferramentas presentes em cada disciplina relacionada à Geomorfologia, os referidos conceitos e habilidades tornar-se-ão um desafio. 


\section{REPRESENTAÇÃO, PENSAMENTO E VISUALIZAÇÃO ESPACIAL}

As representações visuais gráficas são usualmente utilizadas nas aulas e nos livros de geomorfologia, principalmente para representações do relevo em carta topográfica, blocodiagramas, perfis topográficos e geológicos. Cada tipo de representação demanda habilidades específicas, podendo ser de natureza matemática, como os perfis topográficos, geométrica (bloco-diagrama), cartográfica (mapas topográficos, geológicos, geomorfológicos) entre outras (SOUZA, 2009; SOUZA e VALADÃO, 2015), utilizadas de maneira individualizadas ou inter-relacionadas na resolução de um problema. Na interação sujeito, linguagem, representação durante os estudos geográficos e geomorfológicos está presente o pensamento espacial. Este é entendido pela Learning to Think Spatially (NRC 2006) como a capacidade de visualizar e interpretar dados referentes ao espaço, que são captados, codificados e armazenados na memória (SINTON, 2011), sendo mobilizados durante a compreensão de mapas, gráficos, diagramas como representações espaciais. Conforme Roger Downs (NRC, 2006), o pensamento espacial é fundamentado na construção do amalgamo de três elementos: conceitos espaciais, ferramentas/instrumentos de representação e processo de raciocíneo. Para exemplificar essa ideia, traz-se a seguinte colocação:

A transposição da imagem em planta (bidimensional) para a imagem em volume (tridimensional) demanda do observador a habilidade de perceber $\mathrm{o}$ posicionamento das linhas $(\mathrm{X}, \mathrm{Y}, \mathrm{Z})$ no espaço e não mais na base plana. Para isso, é necessário ao observador criar em sua mente a geometria tridimensional da imagem. Esta fica mais difícil quando se trabalha com formas cujas superfícies e estruturas não são retilíneas como o cubo, por exemplo, e sim irregulares como a topografia de áreas dissecadas a partir da erosão diferencial. Nesse caso se tem dois obstáculos a serem superados. $\mathrm{O}$ primeiro o de decodificar e visualizar a posição das linhas no espaço; o segundo o de entender a sinuosidade das linhas como expressão da dissecação do modelado (SOUZA, 2003, p.161).

A representação tridimensional (3D) possibilita a visão da forma e da relação entre as partes que compõem a porção ou unidade representada em modelos, geralmente, reduzidos, físicos (CECCHET,1982) ou virtuais. A apreensão desses modelos envolve a habilidade de conceber as partes da forma e de sua visualização espacial. Esta consiste na manipulação de problemas visuais complexos, imaginando os movimentos relativos das partes internas de uma imagem, e é entendida como uma das habilidades espaciais, que compreendem, também, a rotação mental e a percepção espacial (CHOI, 2001). Conforme Linn e Petersen (1985), a percepção espacial, a rotação mental e a visualização espacial constituem componentes distintos da capacidade espacial. 
Testes realizados com alunos de geologia, por Kali e Orion (1996) e mais tarde por Souza (2003, 2009), mostraram que alunos iniciantes demonstraram muita dificuldade para perceber as estruturas internas, representadas em bloco-diagrama e, os tipos de erros apresentados foram chamados de non-penetrative e penetrative. Segundo Ishikawa e Kastens (2005) o non-penetrative refere-se às respostas baseadas, inteiramente, na informação exposta na superfície visível do bloco, enquanto a penetrative compreende respostas, mesmo que erradas, que buscavam inferir a estrutura geológica interna (SOUZA, 2009, p. 166), conforme exemplificado na figura 6 .

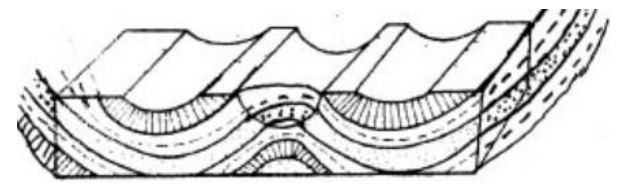

Representação (a)

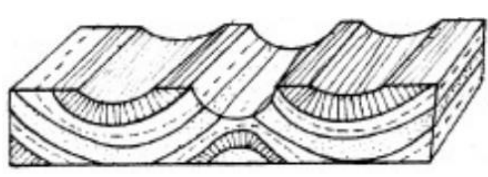

Representação (b)

Fonte: Souza, 2009.

Figura 6: Exemplo de representações com visão somente externa (a) (non-penetrative) e externa e interna (b) (penetrative).

Nas representações da figura 6 está o resultado de alguns testes realizados, por Souza (2009), com alunos de geografia. Foi solicitado aos graduandos, durante a disciplina de Geomorfologia Climática e Estrutural, que representassem na face superior e lateral direita do bloco-diagrama o comportamento/posição das rochas observadas na face frontal. Segundo Souza (2009), o resultado das representações permitiu verificar que $46 \%$ dos alunos, de uma classe com 23 estudantes, demonstraram dificuldades, enquanto 54\% realizaram a representação satisfatoriamente.

A dificuldade com a visão penetrative nos estudos das geociências favorece o resultado insatisfatório durante práticas, em sala de aula ou no campo, que demandam perceber e visualizar espacialmente a forma de relevo, considerando os seus atributos externos e internos, principalmente, quando expostos parcialmente.

Girar mentalmente um objeto para ver cenas de diferentes pontos de vista, constitui habilidade rotacional da imagem, utilizada pelo geólogo e geomorfólogo em situações que precisam ver as estruturas de uma perspectiva diferente da que é observável em campo ou no mapa geológico e, ainda, na simulação imaginária do processo de formação de uma superfície inicialmente plana, que passa a apresentar dobras e falhas (SOUZA, 2009). 
Ainda segundo a autora, no estudo em campo, habilidades como: ser capaz de se deslocar no espaço real; orientar-se e reconhecer no real a posição de dados selecionados a partir de um todo complexo; elaborar uma síntese dos elementos observados a partir de uma imagem mental coerente com o terreno, com a estratigrafia e com a estrutura da área considerada, são habilidades espaciais básicas para o geólogo e igualmente para o geógrafo e o geomorfólogo. Para isso, os geógrafos devem ser capazes de identificar no campo elementos-chave para a geomorfologia, como características morfológicas (altitude, altura, tipologias de vertentes, topos e vales); agentes e processos geomorfológicos atuantes (retirada, transporte de deposição) e atentar-se para a relação tempo-espaço dos elementos separados e integrados na interpretação. O processo cognitivo para identificar, comparar, associar e sintetizar os elementos e aspectos considerados no campo, ou na representação gráfica, mobiliza conhecimentos espaciais, conceitos e teorias, em modelos mentais, para explicar a espacialidade do fenômeno, no caso o geomorfológico.

\section{CONSIDERAÇÕES FINAIS}

O que ensinar? Para quem e por quê? Indiretamente, essas três perguntas perpassaram a linha de raciocínio construída neste texto e que subsidiam, também, a ideia dos três desafios. Pensar o ensino não compreende considerar somente um rol de conteúdo, organizado em currículos de formação a ser apresentado para os futuros profissionais geógrafos, seja o técnico ou o professor. Considerar o conhecimento prévio dos graduandos, as dificuldades presentes durante o processo ensino-aprendizagem do conteúdo de geomorfologia, as habilidades necessárias a esses sujeitos e suas habilidades cognitivas, as expectativas e perspectivas de todos os sujeitos envolvidos no processo de ensinoaprendizagem são aspectos/desafios que fazem parte do ensino, em especial o de geomorfologia. Acredita-se que questionamentos e problematizações referentes à concepção de ensino-aprendizagem e aos desafios podem aparecer entre os docentes. Esses elementos são importantes para ampliar os diálogos sobre ensino de geomorfologia.

Nessa discussão, não se nega a existência dos aspectos/desafios referentes à logística e recursos necessários para os trabalhos teórico-práticos; o número de alunos por turma; a carga horária destinada às disciplinas de geomorfologia, entre outros aspectos, que podem inviabilizar ou dificultar o ensino-aprendizagem e o trabalho do professor. A importância do tema está justamente em refletir o ensino com base em outra perspectiva, diferentemente do 
que se tem visto. Sabe-se que esses aspectos fazem parte da realidade de outros cursos de formação profissional. Portanto, para tal fato, cabe outro tipo de discussão sobre a formação profissional, referente às políticas públicas de formação na qual cabem discutir infraestrutura, qualidade da formação, valorização do professor, pesquisa, extensão, entre outros.

\section{REFERÊNCIAS}

AB'SABER, A. N. Um conceito de geomorfologia a serviço das pesquisas sobre o quaternário. Geomorfologia, São Paulo: Instituto de Geografia-USP, n.18, p. 1-22, 1969.

AFONSO, A. E. Perspectivas e possibilidades do ensino e da aprendizagem em Geografia Física na formação de professores de Geografia. Universidade Federal do Rio de Janeiro, 2015 (Tese de doutorado).

ALARCÃO, I. Contribuição da didática para a formação de professores - reflexão sobre o seu ensino. In: PIMENTA, S. G. (org.) Didática e formação de professores: percursos e perspectivas no Brasil e em Portugal. São Paulo: Cortez, 2008, p.159-190.

ALTET, M. Análise das práticas dos professores e das situações pedagógicas. Porto: Porto Editora, 2000.

BATES, A. W. Technology: open learning and distance education. Nova York: Routledge, 1995.

BERTOLINI, W. Z. O ensino do Relevo: Noções e propostas para uma didática da Geomorfologia. 2010. 124 f. Dissertação de Mestrado. Programa de Pós-Graduação do Departamento de Geografia da Universidade Federal de Minas Gerais.

CARVALHO, A. L. P. Geomorfologia e geografia escolar: o ciclo geográfico davisiano nos manuais de metodologia do ensino (1925-1993). 1999. 231 f. Dissertação (Mestrado em Educação) - Faculdade de Educação, Universidade Federal de Santa Catarina, Florianópolis, Santa Catarina, 1999.

CASSETI, V. Ambiente e apropriação do relevo. São Paulo: Contexto, 1991.

CECCHET, J. M. Iniciação cognitiva do mapa. 1982. 186 f. Dissertação (Mestrado em Geografia) - Instituto de Geociências e Ciências Exatas, Universidade Estadual Paulista, Rio Claro, São Paulo, 1982. 
CHOI, J. Sex Differences in spatial abilities in humans: two levels of explanation. In: VOKEY, J. R.; ALLEN, S. W. Psychological Sketches. 5. ed. Lethbridge: Department of Psychology and Neuroscience, University of Lethbridge, 2001.

CRUZ, L. M. O ensino de geomorfologia e o uso de recursos didáticos tecnológicos. Tese de doutorado no Programa de Pós-Graduação em Geografia Uberlândia, UFU, 2017. 229p.

HERNÁNDEZ, F. Transgressão e Mudança na Educação - Os Projetos de Trabalho. Porto Alegre. Editora ArtMed. 1998.

ISHIKAWA, T.; KASTENS, K. A. Why some students have trouble with maps and other spatial representations. Journal of Geoscience Education. v. 53, n. 2, marc. p. 184-197, 2005 .

KALI, Y.; ORION, N. Spatial abilities of High-school students in the perception of Geologic structures. Journal of research in Science Teaching, v. 33, n. 4, p. 369-391m, 1996.

KÖHLER, H. C. A escala na análise geomorfológica. Revista Brasileira de Geomorfologia, vol. 2, n. 1, p. 21-33, 2002.

LINN, M. C., e PETERSEN, A. C. Emergence and characterization of sex differences in spatial ability: A meta-analysis. Child Development, 1985, 1479-1498.

MARINHO, E. G. do A. Desenvolvimento e natureza da geomorfologia. Cadernos IG/UNICAP. Campinas: UNICAMP, v. 5, n. 1, p. 9 -21, 1995.

MORAIS, E. M. B. de. O ensino das temáticas físico-naturais na Geografia escolar. Tese. Programa de Pós-graduação em Geografia da Faculdade de Filosofia, Letras e Ciências Humanas da Universidade de São Paulo. 2011, 309 p.

NATIONAL RESEARCH COUNCIL COMMITTEE ON SPATIAL THINKING. Learning to Think Spatially. Washington D.C.: National Academies Press. 2006. Disponível em: https://kindergartenspatialreasoning.wikispaces.com/file/view/Learning\%20to\%20Think\%20 Spatially.pdf/600975454/Learning\%20to\%20Think\%20Spatially.pdf. Acesso em 14.05.2018.

OLIVEIRA, A. S. Contribuição teórico-metodológica para o ensino de Geomorfologia. UNESP, Presidente Prudente, 2010.

POZO, Juan I. Aprendizes e mestres: a nova cultura da aprendizagem. Tradução de Ernani Rosa. Porto Alegre: Artmed, 2002. 
ROQUE, V. de O. A. Os conhecimentos docentes e a abordagem do relevo e suas dinâmicas nos anos finais do ensino fundamental. Instituto de Geociências - UFMG, 2009. ROSS, J. L. S. Geomorfologia. Ambiental e planejamento. São Paulo: Contexto, 1996.

SARAVALI, E. G. Dificuldades de Aprendizagem no Ensino Superior. Reflexões a partir das Perspectivas Piagetianas. Estudos piagetianos \& psicologia clínica e educacional. Campinas, v. 6, n. 2, p. 79-101, jun. 2005.

SCHUMM, S. A.; LICHTY, R. W. Tempo, espaço e causalidade em geomorfologia. Notícia Geomorfológica. Campinas, 13(25), p. 43-62, 1973.

SINTON, D. S. Spatial thinking. In 21st Century Geography: A Reference Handbook, ed. J. Stoltman. Thousand Oaks, CA: Sage Publications, 2011, p. 733-744.

SPIRO, R. J.; FELTOVICH, P.J.; COULSON, R. L. e ANDERSON, D. K. Knowledge acquisition for application: cognitive felxibility and transfer in complex contente domains. Technical Rport, $\mathrm{n}^{\circ}$ 409. University of Illinois, 1987.

SOUZA, C. J. de O. Geomorfologia no ensino superior: difícil, mas interessante! Por quê? Uma discussão a partir dos conhecimentos e das dificuldades entre graduandos de geografia - IGC/UFMG. 2009. UFMG, (Tese de doutorado no Programa de Pós-Graduação em Geografia, IGC/UFMG, 2009).

SOUZA, C. J. O. Ensino de Geomofologia contextualizado na transposição didática. In: SIMPÓSIO DE GEOGRAFIA FÍSICA APLICADA, 10, 2003, Rio de Janeiro, Anais... Rio de Janeiro: UERJ, nov. 2003. p. 156-165, 2003.

SOUZA, C. J. de O. e VALADÃO, R. C. Habilidades e competências no raciocínio e na prática da Geomorfologia: proposta para a formação em Geografia. GEOUSP (Online), São Paulo, v. 19, n. 1, p. 093 - 108, jan./abr. 2015

TRICART, J. L. F. Geomorphology for the future: geomorphology for development and development for geomorphology. In: GARDINER, V. INTERNATIONAL GEOMORPHOLOGY, 5, 1986, New York. - Proceedings of the First International Conference on Geomorphology: New York: Johb Wiley \& Sons, 1987. p. 35-44.

VITTE, Antônio C. Os fundamentos metodológicos da geomorfologia e a sua influência no desenvolvimento das ciências da terra. In: VITTE, A. C.; GUERRA, A. J. T. Reflexões sobre a Geografia física no Brasil. Rio de Janeiro: Bertrand Brasil, 2004. p. 23-48. 
Revista de Geografia (Recife) V. 35, No. 4 (especial XII SINAGEO), 2018

YENEMOTO, H. W. Proposta de integração entre ensino, aprendizagem, comunicação e virtualidade: uma arquitetura de reestruturação para o ensino superior. 2004. 347 f. Tese (Doutorado em Engenharia de produção) - Faculdade de Engenharia, Universidade Federal de Santa Catarina, Florianópolis, 2004. 